\title{
Effect of zinc nanoparticles on embryo and chicken growth, and the content of zinc in tissues and faeces
}

\author{
M. Łukasiewicz ${ }^{1}$, A. Łozicki ${ }^{2}$, N.H. Casey ${ }^{3}$, A. Chwalibog ${ }^{4}$, J. Niemiec ${ }^{1}$, A. Matuszewski ${ }^{1}$, M. \\ Sosnowska ${ }^{2}$, M. Wierzbicki ${ }^{2}$, M. Zielinska ${ }^{2}$, J. Bałaban $^{2}$ \& E. Sawosz ${ }^{2 \#}$ \\ ${ }^{1}$ Department of Poultry Breeding, Warsaw University of Life Sciences, Warsaw, Poland \\ ${ }^{2}$ Department of Animal Nutrition and Biotechnology, Warsaw University of Life Sciences, Warsaw, Poland \\ ${ }^{3}$ Department of Animal and Wildlife Sciences, University of Pretoria, South Africa \\ ${ }^{4}$ Department of Veterinary and Animal Sciences, University of Copenhagen, Copenhagen, Denmark
}

(Received 11 February 2019; Accepted 22 November 2019; First published online 10 March 2020)

Copyright resides with the authors in terms of the Creative Commons Attribution 4.0 South African Licence.

See: http://creativecommons.org/licenses/by/4.0/za

Condition of use: The user may copy, distribute, transmit and adapt the work, but must recognise the authors and the South African Journal of Animal Science.

\begin{abstract}
The hypothesis was that owing to their high bioavailability, zinc oxide nanoparticles (NanoZnO) can effectively replace ( $\mathrm{Zn})$ salts and reduce $\mathrm{Zn}$ excretion with faeces. The objective of this study was to investigate the effects of NanoZnO on the development of chicken embryos, the growth of broiler chickens, and $\mathrm{Zn}$ excretion with faeces. At day 1 of incubation, 120 eggs were randomly divided between a control group (not injected) and groups injected with a hydrocolloid of NanoZnO in increasing concentrations (50, $100,500 \mathrm{mg} / \mathrm{L}$ ). At day 19 of incubation, no differences were observed in the bodyweight, but 100 and 500 $\mathrm{mg} / \mathrm{L}$ affected liver and heart weights, indicating that high levels of NanoZnO may induce differential organ development. In the subsequent experiment, 308 chickens were randomly divided into six groups. The control diet was supplemented with $55 \mathrm{mg} \mathrm{Zn/kg}$ (standard level), the 0 group received no Zn supplement, and groups fed NanoZnO received $25 \%, 50 \%, 75 \%$, and $100 \%$ of the standard level. The $100 \%$ replacement of $\mathrm{ZnO}$ with NanoZnO increased the chickens' bodyweight compared with the standard level of $\mathrm{ZnO}$, but to the same level as the diet without $\mathrm{ZnO}$ supplementation. Furthermore, NanoZnO did not reduce the content of $\mathrm{Zn}$ in faeces, which was only significantly lower in the group without $\mathrm{ZnO}$ supplementation in comparison with other groups. The results indicate that the replacement of $\mathrm{ZnO}$ with NanoZnO had no negative effects on chicken growth. Compared with $\mathrm{ZnO}$, NanoZnO did not reduce $\mathrm{Zn}$ excretion with faeces.
\end{abstract}

Keywords: broiler, development, excretion, mineral, nanonutrition

\#Corresponding author: ewa_sawosz@sggw.pl

\section{Introduction}

Nanoparticles are increasingly being considered for inclusion in formulated diets and supplementary nutrition for livestock production. The biological advantages of nano nutraceuticals include greater bioavailability owing to formation of micelles for absorption with lower residence in the intestinal tract, less excretion via the faeces, and easier movement across membranes (Gopi et al., 2017). Zinc is an essential supplement in poultry diets and plays crucial roles in the regulation of growth, the immune system and reproduction.

Nanoparticles of $\mathrm{Zn}$, primarily zinc oxide nano particles (NanoZnO) are potential alternatives to inorganic and organic $\mathrm{Zn}$ sources, specifically as an enhancer of broiler growth performance, as reviewed by Swain et al. (2016) and indicated by Fathi (2016), Asheer (2017), Badawi and Behairy (2017), Ali et al. (2017) and Bami et al. (2018). However, although the chickens supplemented with NanoZnO had a higher body gain and better feed conversion rate (FCR) than birds without Zn supplement, the growth performance was not different between groups fed with different $\mathrm{Zn}$ sources (inorganic, organic and nano) (Badawi et al., 2017). The results of growth responses are not consistent, and render it difficult to draw general conclusions, largely owing to the lack of characterization (size, shape) of these nanoparticles and the varying content of $\mathrm{Zn}$ in dietary feed ingredients. 
Post-hatch survival, growth and development are continuations of embryonic survival, growth and development, which are dependent on the nutrients in the yolk and albumen that are available to the developing embryo. To this effect, nano-copper ( $\mathrm{NanoCu}$ ) can replace copper $(\mathrm{Cu})$ salts effectively in embryonic and post-hatch health and growth (Mroczek-Sosnowska et al., 2015a, 2015b; MroczekSosnowska et al., 2017; Scott et al., 2016; Scott et al., 2017; Sawosz et al., 2018; Scott et al., 2018).

This research pursued the hypotheses that NanoZnO does not affect embryo growth and that NanoZnO could replace $\mathrm{Zn}$ salts as a health and growth promoter and, given their high reactivity and bioavailability, may reduce the content of $\mathrm{Zn}$ in faeces. The objective of the study was to establish whether NanoZnO could replace $\mathrm{ZnO}$ supplement in the diets of broilers, reducing excretion of $\mathrm{Zn}$ into the environment.

\section{Materials and Methods} Sciences.

Ethical approval for this research is documented in I.dz.Ike 46/2015, Warsaw University of Life

NanoZnO powder (99.8\% purity) was purchased from Sky Spring Nanomaterials Inc., Houston, USA, (Product no. $8410 \mathrm{DL}$ ). For characterization, nanoparticles were suspended in Milli-Q water at a concentration of $50 \mathrm{mg} / \mathrm{L}$ water. The size and shape of the nanoparticles were determined with a JEM2000EX Transmission Electron Microscope at $80 \mathrm{keV}$ (JOEL, Tokyo, Japan). The zeta potential was measured in a colloidal solution of $50 \mathrm{mg} / \mathrm{L}$ NanoZnO using Zetasizer Nano ZS, model ZEN3500 (Malvern Instruments, Worcestershire, UK). Each sample was measured after 120 seconds of stabilization at $25^{\circ} \mathrm{C}$, in 20 replicates. Furthermore, colloidal impurities were determined using a Z-5300 polarised flame atomic absorption spectrometer (Hitachi-Science \& Technology, Tokyo, Japan).

The study consisted of Phases 1 and 2, in which Phase 1 examined the effects of NanoZnO in developing embryos, and Phase 2 examined the effects on post-hatch growth and development.

In Phase 1, 120 eggs were randomly divided into four groups of 30 eggs per group. The hydrocolloids of NanoZnO were injected at the first day of incubation in concentrations 50,100 and $500 \mathrm{mg} / \mathrm{L}$. The control group (C) was not injected. At 19 days of incubation, the body and organ weights and biochemical indices of blood serum were measured. The administration of the NanoZnO incubation procedure and evaluation of embryo growth were performed as described by Pineda et al. (2013).

In Phase 2, given that $\mathrm{Zn}$ nanoparticles in powder form were dusty and were added to the basal diets (Table 1) feeds in small quantities, it would have been difficult to obtain a homogeneous feed mixture. This limitation was overcome by mixing the NanoZnO with starch as a carrier before being added to the diets. NanoZnO powder and starch were suspended in ultrapure water in the proportion 1: 100 (NanoZnO: starch, $\mathrm{w} / \mathrm{w}$ ) and were subsequently dried to powder with a dry matter content not less than $90 \%$. The NanoZnO and starch complex was then added to a premix (Rovmix Broiler Grower, 0.5\%, DSM) and the premix (Table 2) was added to the basal diets. Dry matter, nitrogen, crude fat, crude fibre and energy contents were determined in feed samples (Pineda et al., 2012).

Day-old Ross 308 chicks were obtained from a commercial hatchery and were randomly divided into six groups of six birds each, with a treatment allocated to a group, and six replicates in a treatment. The treatments of this post-hatch growth phase were designed to include a positive control (C) of $55 \mathrm{mg} / \mathrm{kg} \mathrm{ZnO}$ in the diet as the standard that was in the mineral-vitamin premix, a group without $\mathrm{ZnO}$, which received no $\mathrm{Zn}$ supplement (0) and groups that were fed with complexes of NanoZnO and starch received 25\%, 50\%, $75 \%$, and $100 \%$ of the standard level of $\mathrm{Zn}$ used in the control group (Table 3). The calculated total levels of exposure to dietary $\mathrm{Zn}$ were 114 and $59 \mathrm{mg} / \mathrm{kg}$ provided as $\mathrm{ZnO}$, and 72.8, 86.5, 100 and $114 \mathrm{mg} / \mathrm{kg}$ provided as NanoZnO. The treatment period was from day 1 for 42 days. 
Table 1 Ingredients and chemical composition of the basal starter and grower diets

\begin{tabular}{lcc}
\hline Ingredients (\%) & Starter (1 - 14 days) & Grower (15 - 42 days) \\
\hline Wheat & 45.10 & 47.50 \\
Soybean meal & 25.65 & 22.00 \\
Maize & 10.00 & 10.00 \\
Rape meal & 10.00 & 10.00 \\
Soybean oil & 5.23 & 7.19 \\
Dicalcium phosphate & 2.25 & 1.54 \\
Alimet 88\% & 0.33 & 0.27 \\
L-lysine hydrochloride 98\% & 0.24 & 0.21 \\
Sodium chloride & 0.21 & 0.22 \\
Chalk & 0.20 & 0.32 \\
Sodium carbonate & 0.15 & 0.10 \\
L-Threonine & 0.14 & 0.15 \\
Mineral-vitamin premix & 0.50 & 0.50 \\
Analysed chemical composition (\%) & & 19.42 \\
Crude protein & & 6.73 \\
Crude fat & 21.70 & 3.37 \\
Crude fibre & 4.95 & 13.31 \\
Metabolizable energy, calculated (MJ/kg DM) & 3.32 & 12.56 \\
\hline
\end{tabular}

The chickens were kept in groups during the first week and then individually in metabolic cages until they were 42 days old. The temperature was $32{ }^{\circ} \mathrm{C}$ in the first week, and lowered $2{ }^{\circ} \mathrm{C}$ weekly to $20^{\circ} \mathrm{C}$. The average humidity was $60 \%$ and 24 -hour lighting was applied. The birds had free access to water and were fed ad libitum. The applied feed mixtures were starter for chickens 1 - 14 days and grower for 15 - 42 days (Table 2). Bodyweight (BW) was recorded at 1, 14, 35 and 42 days. The feed intake was registered daily as total values for each group. Individual excreta were collected daily over the period 28 to 35 days to determine the amount of $\mathrm{Zn}$ excreted.

The animals were euthanised at 42 days following a 12 hour fast. Carcass yield (\%) and the weight yield of leg and breast muscles, gizzard, liver, heart and adipose tissue were measured following 24-hour air chilling at $4{ }^{\circ} \mathrm{C}$. The tissue samples, organs and excreta ( $\mathrm{n}=6$ per group) were kept at $-80{ }^{\circ} \mathrm{C}$ for further analyses. The $\mathrm{Zn}$ content in the feed, breast muscle, liver and femoral bone at 42 days, and in excreta (28 to 35 days) was determined using a Z-5300 polarized flame atomic absorption spectrometer (Hitachi High-Tech Science Corporation, Tokyo, Japan).

The data distribution was evaluated using the Shapiro-Wilk test. Data were normally distributed and the results were analysed with one-way analysis of variance (ANOVA) using Statgraphics ${ }^{\circledR}$ Centurion XVI software (StatPoint Technologies, Inc., Warrenton, Virginia, USA) at a significance level of $P<0.05$. 
Table 2 Composition of the mineral-vitamin premix to which zinc was added to administer treatments

\begin{tabular}{|c|c|c|}
\hline Ingredient & Unit & Quantity \\
\hline A (retinol acetate) & $\mathrm{IU} / \mathrm{kg}$ & 2200000 \\
\hline D3 (E671) & $\mathrm{IU} / \mathrm{kg}$ & 500000 \\
\hline E (di-alpha-tocopherol acetate) & $\mathrm{mg} / \mathrm{kg}$ & 10000 \\
\hline D (D-pantothenate calcium) & $\mathrm{mg} / \mathrm{kg}$ & 2722 \\
\hline K3 (MNB) & $\mathrm{mg} / \mathrm{kg}$ & 500 \\
\hline B1 (thiamine mononitrate) & $\mathrm{mg} / \mathrm{kg}$ & 400 \\
\hline B2 (riboflavin) & $\mathrm{mg} / \mathrm{kg}$ & 1400 \\
\hline B6 (pyridoxine hydrochloride) & $\mathrm{mg} / \mathrm{kg}$ & 800 \\
\hline B12 (cyanocobalamin) & $\mu \mathrm{g} / \mathrm{kg}$ & 400 \\
\hline Niacin (nicotinic acid) & $\mathrm{mg} / \mathrm{kg}$ & 8000 \\
\hline Folic acid & $\mathrm{mg} / \mathrm{kg}$ & 200 \\
\hline Biotin & $\mu \mathrm{g} / \mathrm{kg}$ & 30000 \\
\hline Choline chloride & $\mathrm{mg} / \mathrm{kg}$ & 60000 \\
\hline Copper & $\mathrm{mg} / \mathrm{kg}$ & \\
\hline Zinc (zinc oxide) & \multicolumn{2}{|c|}{ Amount depending on the treatment applied } \\
\hline Manganese (manganese oxide) & $\mathrm{mg} / \mathrm{kg}$ & 14000 \\
\hline Iodine (calcium iodate) & $\mathrm{mg} / \mathrm{kg}$ & 120 \\
\hline Selenium (sodium selenate) & $\mathrm{mg} / \mathrm{kg}$ & 70.0 \\
\hline Iron (iron sulphate) & $\mathrm{mg} / \mathrm{kg}$ & 9000 \\
\hline Citric acid & $\mathrm{mg} / \mathrm{kg}$ & 19.0 \\
\hline Etoxyquin & $\mathrm{mg} / \mathrm{kg}$ & 34.8 \\
\hline Propyl gallate & $\mathrm{mg} / \mathrm{kg}$ & 5.4 \\
\hline Calcium carbonate $25.07 \%$ & $\mathrm{~g} / \mathrm{kg}$ & 251 \\
\hline Magnesium $0.22 \%$ & $\mathrm{mg} / \mathrm{kg}$ & 2200 \\
\hline
\end{tabular}

Table 3 Zinc sources and content of zinc oxide and nano-zinc oxide to be used in the experimental diets

\begin{tabular}{|c|c|c|c|c|c|c|}
\hline \multirow{2}{*}{$\begin{array}{l}\text { Zinc }(Z n) \text { source } \\
\text { Zn (\%) of standard level }{ }^{1}\end{array}$} & \multicolumn{2}{|c|}{ Zinc oxide } & \multicolumn{4}{|c|}{ Nano-zinc oxide } \\
\hline & 100 & 0 & $25 \%$ & $50 \%$ & $75 \%$ & $100 \%$ \\
\hline $\mathrm{Zn}(\mathrm{mg} / \mathrm{kg})$ in premix & 11000 & 0 & 2750 & 5500 & 8250 & 11000 \\
\hline Zn supplement $(\mathrm{mg} / \mathrm{kg})$ diet $^{2}$ & 55 & 0 & 13.8 & 27.5 & 41.3 & 55.0 \\
\hline Zn total $(\mathrm{mg} / \mathrm{kg}) \operatorname{diet}^{3}$ & 114 & 59 & 72.8 & 86.5 & 100.0 & 114.0 \\
\hline
\end{tabular}

${ }^{1}$ Level of $\mathrm{Zn}$ reduction compared with the standard level of $55.0 \mathrm{mg} / \mathrm{kg}$ diet: $100 \%$

${ }^{2}$ Level of $Z n$ supplemented from premix in a diet

3 Total level of $\mathrm{Zn}$ from premix + feed ingredients in the grower diet

\section{Results}

NanoZnO were slightly angular, rounded or elongated with an average size of $37 \mathrm{~nm}(10-70 \mathrm{~nm})$ (Figure 1). The specific surface area was $30-50 \mathrm{~m}^{2} / \mathrm{g}$. The mean zeta potential of the colloid was $-32 \mathrm{mV}$, which indicated an intermediate stability of the solution. The total impurities were below $0.01 \%$. 


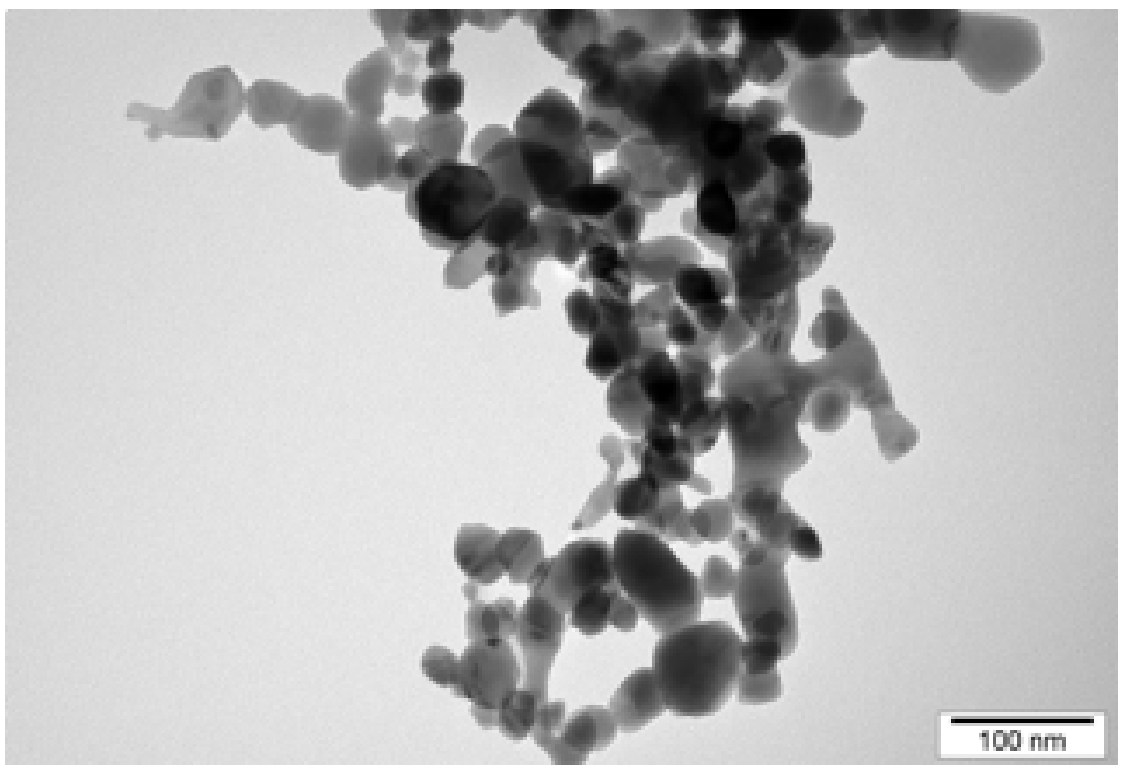

Figure 1 Image of zinc oxide nanoparticles by transmission electron microscopy

Live embryos at 19 days of incubation constituted $67 \%$ in the NanoZnO-treated groups compared with $73 \%$ in the control group. Bodyweights were not significantly different between groups (Table 4). However, groups treated with 100 and $500 \mathrm{mg} / \mathrm{L}$ had significantly higher heart weights than the other groups, while liver weights were lower in NanoZnO groups compared with the control.

Table 4 Pre-hatch embryo and organ weights of chicks at day 19 of incubation

\begin{tabular}{lccc}
\hline Treatment $^{1}(\mathrm{mg} / \mathrm{L})$ & Embryo, $\mathrm{g}$ & Heart, g & Liver, $\mathrm{g}$ \\
\hline $0(\mathrm{C})$ & 43.9 & $0.44^{\mathrm{B}}$ & $1.21^{\mathrm{Aa}}$ \\
50 & 41.2 & $0.36^{\mathrm{B}}$ & $0.95^{\mathrm{B}}$ \\
100 & 43.3 & $0.51^{\mathrm{A}}$ & $1.13^{\mathrm{A}}$ \\
500 & 42.1 & $1.13^{\mathrm{A}}$ & $1.03^{\mathrm{b}}$ \\
$\mathrm{SE}$ & 1.0 & 0.03 & 0.04 \\
$P$-value & 0.20 & 0.005 & 0.000 \\
\hline
\end{tabular}

${ }^{1} \mathrm{C}$ : control; treated with 50,100 and $500 \mathrm{mg} / \mathrm{kg}$ of $\mathrm{ZnO}$ nanoparticles

${ }^{\mathrm{a}, \mathrm{b}}$ Significant differences at $P \leq 0.05 ;{ }^{\mathrm{A}, \mathrm{B}}$ Significant differences at $P \leq 0.01$

The only differences in blood biochemical parameters were higher concentrations of alanine aminotransferase (ALT) and lower triglycerides (TRG) in groups treated with 100 and $500 \mathrm{mg} / \mathrm{L}$ of NanoZnO (Table 5).

Bodyweight at 35 days did not differ significantly among the groups. At 42 days, the BWs of the ZnOsupplementation (0) and the $100 \%$ NanoZnO groups were significantly higher than the control. However, BW did not differ between 0 and NanoZnO groups (Table 6). Feed conversion ratio was measured on a group basis, which prevented statistical comparisons, but numerically FCR was higher (1.72) in the control relative to other groups (1.63). No mortality was recorded. 
Table 5 Biochemical indices in the blood serum of chicken embryos as affected by level of supplementation with zinc oxide nanoparticles

\begin{tabular}{|c|c|c|c|c|c|c|}
\hline & \multicolumn{4}{|c|}{ Treatment $^{1}$} & \multirow{2}{*}{ SE } & \multirow{2}{*}{$P$-value } \\
\hline & Control & 50 & 100 & 500 & & \\
\hline AST (U/l) & $133^{A}$ & $122^{A}$ & $72.0^{\mathrm{B}}$ & $122^{\mathrm{A}}$ & 17.0 & 0.017 \\
\hline ALT (U/l) & $11.6^{\mathrm{B}}$ & $9.90^{\mathrm{B}}$ & $20.6^{A}$ & $17.0^{\mathrm{A}}$ & 1.71 & 0.000 \\
\hline ALP (U/I) & 2222 & 2284 & 2540 & 2444 & 254.4 & 0.619 \\
\hline Glc $(\mathrm{mmol} / \mathrm{l})$ & 277 & 263 & 260 & 249 & 10.4 & 0.154 \\
\hline $\mathrm{Cr}(\mathrm{mmol} / \mathrm{l})$ & $0.31^{\mathrm{ab}}$ & $0.37^{\mathrm{a}}$ & $0.27^{b}$ & $0.32^{\mathrm{ab}}$ & 0.271 & 0.014 \\
\hline TP $(\mathrm{mmol} / \mathrm{l})$ & 20.5 & 19.5 & 22.5 & 17.5 & 2.69 & 0.415 \\
\hline ALB $(\mathrm{mmol} /)$ & 9.50 & 9.50 & 10.0 & 9.50 & 1.141 & 0.970 \\
\hline $\mathrm{TC}(\mathrm{mmol} / \mathrm{l})$ & 360 & 390 & 415 & 334 & 22.4 & 0.020 \\
\hline TRG (mmol/l/) & $84.4^{\mathrm{A}}$ & $86.7^{\mathrm{A}}$ & $71.9^{B}$ & $71.4^{\mathrm{B}}$ & 3.70 & 0.001 \\
\hline LDH (U/I) & 655 & 691 & 628 & 660 & 37.9 & 0.528 \\
\hline $\mathrm{Ca}(\mathrm{mmol} / \mathrm{l})$ & 9.00 & 10.2 & 9.70 & 9.60 & 0.492 & 0.246 \\
\hline $\mathrm{P}(\mathrm{mmol} / \mathrm{l})$ & 6.51 & 5.82 & 5.71 & 5.47 & 1.053 & 0.051 \\
\hline
\end{tabular}

NanoZnO: zinc oxide nanoparticles , AST: aspartate aminotransferase, ALT: alanine aminotransferase, ALP: alkaline phosphatase, Glc: d-glucose, Cr: Creatinine, TP: total protein, ALB: albumin, TC: number of white blood cells, TRG: triglycerides, LDH: lactate dehydrogenase, Ca: calcium, P: phosphorus

${ }^{1} \mathrm{C}$ : control; and treated with 50,100 and $500 \mathrm{mg} / \mathrm{kg}$ of $\mathrm{ZnO}$ nanoparticles

${ }^{\mathrm{a}, \mathrm{b}}$ Significant differences at $P \leq 0.05 ;{ }^{\mathrm{A}}, \mathrm{B}$ Significant differences at $P \leq 0.01$

Table 6 Weights of chickens ( $\mathrm{g}$ ) over time as affected by level of supplementation with zinc oxide nanoparticles

\begin{tabular}{lrrrr}
\hline Treatment $^{1}$ & \multicolumn{4}{c}{ Age (days) } \\
\cline { 2 - 5 } & 0 & 14 & 35 & 42 \\
\hline C (55 mg/kg) & 45 & 417 & 1936 & $2425^{\mathrm{b}}$ \\
$0 \%$ & 43 & 376 & 2014 & $2612^{\mathrm{a}}$ \\
$25 \%$ & 46 & 370 & 1927 & $2486^{\mathrm{ab}}$ \\
$50 \%$ & 44 & 408 & 1975 & $2516^{\mathrm{ab}}$ \\
$75 \%$ & 44 & 415 & 2094 & $2652^{\mathrm{ab}}$ \\
$100 \%$ & 44 & 412 & 2063 & $2706^{\mathrm{a}}$ \\
SEM & 1 & 16 & 84 & 100 \\
$P$-value & 1 & 0.192 & 0.703 & 0.042
\end{tabular}

\footnotetext{
${ }^{1}$ C: control; 0: without zinc oxide (ZnO) nanoparticles; $25 \%, 50 \%, 75 \%$, and $100 \%$ in groups provided with ZnO nanoparticles in proportion to the control

${ }^{a, b}$ Significant differences at $P \leq 0.05$
}

The analysis of carcasses showed that the $\mathrm{Zn}$ content of leg muscle was highest in the control and in the 0 group. The dressing percentage and the content of breast muscle and giblets were not affected (Table 7). 
Table 7 Dressing percentage and carcass content of chickens (\%) as affected by level of supplementation with zinc oxide nanoparticles

\begin{tabular}{|c|c|c|c|c|c|c|}
\hline \multirow{2}{*}{ Treatment $^{1}$} & \multirow{2}{*}{$\begin{array}{c}\text { Dressing } \\
\text { percentage }\end{array}$} & \multicolumn{2}{|c|}{ Muscle } & \multicolumn{3}{|c|}{ Giblets } \\
\hline & & Breast & Leg & Gizzard & Liver & Heart \\
\hline C (55 mg/kg) & 79.1 & 27.5 & $20.0^{\mathrm{a}}$ & 1.63 & 2.58 & 0.69 \\
\hline $0 \%$ & 80.6 & 27.1 & $20.0^{\mathrm{a}}$ & 1.77 & 2.05 & 0.61 \\
\hline $25 \%$ & 77.4 & 26.5 & $18.6^{\mathrm{ab}}$ & 1.82 & 2.05 & 0.61 \\
\hline $50 \%$ & 77.9 & 24.9 & $16.2^{\mathrm{b}}$ & 1.68 & 2.19 & 0.93 \\
\hline $75 \%$ & 78.0 & 26.6 & $16.7^{\mathrm{b}}$ & 1.84 & 2.33 & 0.72 \\
\hline $100 \%$ & 76.7 & 27.6 & $18.3^{\mathrm{ab}}$ & 1.35 & 2.08 & 0.67 \\
\hline SE & 1.2 & 1.2 & 0.8 & 0.19 & 0.20 & 0.06 \\
\hline$P$-value & 0.293 & 0.626 & 0.022 & 0.512 & 0.414 & 0.054 \\
\hline
\end{tabular}

Zinc concentration in breast muscle at 42 days did not differ significantly among the groups (Table 8). However, the liver and femoral bone showed some differences, although these were inconsistent. The lowest concentration in faeces was observed in chickens that did not receive the $\mathrm{ZnO}$ supplement and highest in chickens that received 75 and $100 \%$ of $\mathrm{Zn}$ level and in the control.

Table 8 Zinc content (mg/kg DM) of tissues and faeces from chickens provided different levels of dietary supplementation with zinc oxide nanoparticles

\begin{tabular}{lcccc}
\hline Treatment $^{\mathrm{1}}$ & Breast muscles & Liver & Femoral bone & Faeces \\
\hline $\mathrm{C}(55 \mathrm{mg} / \mathrm{kg})$ & 34.0 & $130^{\mathrm{b}}$ & $105^{\mathrm{d}}$ & $281^{\mathrm{AD}}$ \\
$0 \%$ & 34.6 & $164^{\mathrm{a}}$ & $98.1^{\mathrm{Bb}}$ & $164^{\mathrm{B}}$ \\
$25 \%$ & 30.8 & $160^{\mathrm{a}}$ & $113^{\mathrm{a}}$ & $255^{\mathrm{AE}}$ \\
$50 \%$ & 33.0 & $133^{\mathrm{ab}}$ & $108^{\mathrm{abcd}}$ & $243^{\mathrm{AC}}$ \\
$75 \%$ & 25.0 & $121^{\mathrm{b}}$ & $117^{\mathrm{a}}$ & $293^{\mathrm{ADF}}$ \\
$100 \%$ & 34.2 & $105^{\mathrm{b}}$ & $119^{\mathrm{Ac}}$ & $303^{\mathrm{ADF}}$ \\
$\mathrm{SE}$ & 4.3 & 12.0 & 4.3 & 8.6 \\
P-value & 0.627 & 0.031 & 0.040 & 0.000
\end{tabular}

${ }^{1}$ C: control; 0: without zinc oxide (ZnO) nanoparticles; $25 \%, 50 \%, 75 \%$, and $100 \%$ in groups provided with ZnO nanoparticles in proportion to the control

${ }_{a-d}$ Significant differences at $\mathrm{P} \leq 0.05 ;{ }^{A-F}$ Significant differences at $P \leq 0.01$

The treatments had no effects on the biochemical indices of the blood serum (Table 9). 
Table 9 Biochemical indices in the blood serum of chickens provided different levels of dietary supplementation with zinc oxide nanoparticles

\begin{tabular}{lccccccc}
\hline Treatment $^{1}$ & AST, U/l & ALT, U/l & Glc, mmol/dl & Urea, mg/dl & TP, g/l & ALB. g/l & TRG, mg/dl \\
\hline C (55 mg/kg) & 487 & 19.7 & 226 & 8.73 & 24.0 & 16.7 & 22.2 \\
$0 \%$ & 511 & 21.2 & 204 & 6.53 & 26.0 & 16.6 & 20.5 \\
$25 \%$ & 508 & 20.7 & 199 & 9.20 & 23.3 & 15.3 & 19.5 \\
$50 \%$ & 485 & 20.3 & 191 & 8.13 & 24.0 & 15.0 & 18.6 \\
$75 \%$ & 429 & 22.9 & 194 & 7.61 & 24.2 & 16.0 & 18.5 \\
$100 \%$ & 417 & 19.0 & 188 & 7.33 & 24.0 & 15.3 & 20.2 \\
SE & 50 & 3.2 & 10 & 0.97 & 0.8 & 0.6 & 4.2 \\
$P$-value & 0.682 & 0.416 & 0.175 & 0.094 & 0.298 & 0.333 & 0.987 \\
\end{tabular}

\footnotetext{
${ }^{1}$ C: control; 0: without zinc oxide (ZnO) nanoparticles; 25\%, 50\%, 75\%, and 100\% in groups provided with ZnO nanoparticles in proportion to the control

AST: aspartate aminotransferase; ALT: alanine aminotransferase, Glc: glucose; TP: total protein; ALB: albumins; TRG: triglycerides
}

\section{Discussion}

In Phase 1, administration of NanoZnO at the beginning of embryogenesis had no effect on BW, but increased the heart weight and decreased the liver weight of embryos at 19 days. The lack of influence on BW at hatch was also demonstrated by Josuha et al. (2016), who injected NanoZnO at 18 days of incubation, and by Hassan (2018) when the injection took place at the beginning of incubation. The percentage of live embryos was lower in the NanoZnO treated groups than in the Control. This finding, however, is not congruent with those of Josuha et al. (2016) and Hassan (2018), who found no differences in hatchability, albeit using smaller doses of $\mathrm{Zn}$ nanoparticles. Whether the injection per se could affect the hatchability cannot be answered no group was injected with a placebo, but Hassan (2018) demonstrated no differences between embryos administered with nanoparticles and those that were not injected or were injected with phosphate buffered saline.

Comparable results for the effect of NanoZnO on organ weights in the developing embryo could not be traced in the literature. The biochemical indices of blood serum were different only for ALT with an elevated level, and decreased TRG level in the 100 and $500 \mathrm{mg} / \mathrm{L}$ groups. These changes were within the normal range for chickens (Chattopadhyay et al., 2006; Hassan, 2018). The changes are an interesting phenomenon since the ALT was increased significantly in the 100 and $500 \mathrm{mg} / \mathrm{L}$ treatments, and the ratios of AST to ALT, which indicates clinical health in liver function, were 11.5, 12.3, 3.5, and 7.2 for the control and groups that were injected with 50,100 , and $500 \mathrm{mg} / \mathrm{L}$, respectively. This decreasing ratio, aligned with the lower liver mass and increased heart mass, indicated that the higher levels of NanoZnO may induce differential organ development in chicken embryos. Chicken embryos are highly sensitive models for testing potential toxic effects of injected substances by monitoring total and differential organ development rates and survivability of the embryos (Korhonen et al., 1982; Sawosz et al., 2014; Lucht et al., 2018).

In Phase 2, the chickens were kept in metabolic cages. Consequently, the number of animals was limited. However, the experiment was not a performance study, but it included individual measurements of the content of $\mathrm{Zn}$ in faeces, requiring individual cages for quantitative sample collection. The feed intake and FCR were recorded on a group basis. The control group was supplemented with a standard level of $55 \mathrm{mg}$ $\mathrm{Zn}$ per $\mathrm{kg}$ of feed, as recommended by the NRC (1994). The group without ZnO did not receive $\mathrm{Zn}$ supplementation, while the other groups were administered with NanoZnO in incremental proportions of the control (55 mg/kg).

There was no clear indication of differences in BW at 42 days since treatments $0 \%, 25 \%, 50 \%, 75 \%$, and $100 \%$ did not differ. However, the treatment with $100 \%$ of NanoZnO significantly increased BW compared with the standard level of ZnO. Several reports show enhanced growth performance (Lina et al., 2009; Ahmadi et al., 2013; Mishra et al., 2014; Zhao et al., 2014; Khah et al., 2015; Mohammadi et al., 2015; Fathi, 2016; Sahoo et al., 2016; Hassan, 2018), but others show no effects of Zn nanoparticles on BW (Lina et al., 2009; Asheer, 2017; Bami, 2018). The literature is conflicting, and it is impossible to explain incongruence, which might be attributed to the type, size and dose of nanoparticles, experimental design, and differences in feeding and management of chickens. 
The numeric values of FCR indicate that this was improved in the group without $\mathrm{ZnO}$ supplement and in all NanoZnO groups compared with the control group. Improved FCR had been demonstrated by Ahmadi et al. (2013), Zhao et al. (2014), Fathi (2016) and Sahoo et al. (2016) when comparing increased doses of NanoZnO with the standard supplement of Zn. However, when inorganic Zn was replaced with NanoZnO (25 - 100\% replacement), only the 100\% replacement reduced FCR (Asheer, 2017).

It is striking that BW and FCR, although improved by NanoZnO supplementation, were not different from the birds fed without $\mathrm{ZnO}$. The feed ingredient provided $59 \mathrm{mg} \mathrm{Zn} / \mathrm{kg}$ diet, which was sufficient to meet the birds' requirements. In the control, the total amount of $\mathrm{Zn}$ was $114 \mathrm{mg} / \mathrm{kg}$ (feed ingredients $59 \mathrm{mg} / \mathrm{kg}+$ ZnO supplement $55 \mathrm{mg} / \mathrm{kg}$ ), which was probably too high, but nevertheless low enough to avoid causing harmful health effects. The diets with NanoZnO provided increasing levels of Zn (from 73 to $114 \mathrm{mg} / \mathrm{kg}$ ), causing higher body gain and superior FCR to the control group, but no different from the group without ZnO supplementation. This might indicate that the replacement of $\mathrm{ZnO}$ with NanoZnO can enhance chicken performance, but that it is not necessary when the supply of $\mathrm{Zn}$ from feed ingredients covers $\mathrm{Zn}$ requirements. The feed ingredients used in the present diet are standard compounds, suggesting that the results might be applicable to commercial poultry mixtures, which provide enough $\mathrm{Zn}$ from feed ingredients. Nevertheless, this postulate has to be justified in extended performance experiments.

The effect of NanoZnO on dressing percentage has been reported as being both positive (Lina, 2009; Khah et al., 2015) and negative (Sahoo et al., 2016). The present results indicated an absence of effects on dressing percentage and the carcass content of breast muscle and giblets at 42 days. However, the content of leg muscle decreased in NanoZnO-treated groups. Again, it is difficult to compare results from different methodologies, but the findings of Kahah et al. (2015) and Sahoo et al. (2016) showed no effects on the proportion of thigh.

After absorption in the intestine, nanoparticles can enter the bloodstream and be stored in various organs and be distributed independently of the blood circulation (Anjum et al., 2016). In the present experiment, the content of $\mathrm{Zn}$ in breast muscle was generally lower in NanoZnO groups than in the control and 0 groups. The differences between $\mathrm{Zn}$ retained in the liver and femoral bone were not conclusive. Sahoo et al. (2014) noted that NanoZnO could increase Zn content in the tibia bone, liver and blood serum, but that study is not directly comparable with the present study.

The content of $\mathrm{Zn}$ in faeces was significantly lower in the group without $\mathrm{ZnO}$ supplementation, relative to the other groups, which did not differ significantly. The administration of NanoZnO did not reduce $\mathrm{Zn}$ excretion in comparison with the control group. The increased excretion in the faeces with increasing supplementation of NanoZnO can be ascribed to residual non-absorbed dietary $\mathrm{Zn}$ in the digestive tract plus endogenous $\mathrm{Zn}$ that is excreted via the liver and biliary tract and kidneys. As noted, individual feed intake could not be recorded, nor could the total exposure to dietary $\mathrm{Zn}$ calculated. However, the non-significant differences in faecal Zn between groups C, 25\%, 50\%, 75\%, and 100\% could indicate similar homeostatic processes between the treatments. The deduction is that homeostasis of $\mathrm{Zn}$ was not dependent on the level of NanoZnO intake.

The biochemical parameters of the blood serum were not affected. The present results correspond with findings by Fathi (2016) and Hassan (2018), but contradict those of Ahmadi et al. (2013), Mishra et al. (2014), and Sahoo et al. (2014), who did identify some effects. As in performance, the literature is inconsistent. Furthermore, there was no mortality in any of the groups, indicating good health status of all birds.

It emerged from Phases 1 and 2 that differential development may have been induced in embryonic development that was carried through to the post-hatch growth and development. The embryos showed increased liver and heart weights and the chickens showed lighter livers with increasing NanoZnO, though non-significant, and significant differential development of the leg muscle in which the $50 \%, 75 \%$, and $100 \%$ treatments were lower that the $\mathrm{C}$ and 0 groups. The biochemical indices also showed interesting tendencies. It would appear, though the results do not show significance, that the NanoZnO could have an effect at mitochondrial level. The embryos show decreasing TP and increasing $\mathrm{Cr}$. Using these few values, the correlation is -0.6 , and reciprocal. Because the leg muscle is lower percentagewise, this may indicate differential growth that is affecting red muscle fibre. In early development, all the muscle fibres have the characteristic of red aerobic muscles. As development advances in chickens, a differentiation occurs with the breast muscles, which become white muscle types, glycolytic, with the leg muscle, for example the gastrocnemius, retaining red muscle fibre characteristics.

\section{Conclusion}

Injection of NanoZnO into eggs at the start of incubation did not affect BW, survival rate and health status of embryos in the final stage of embryogenesis. There was an indication that concentrations greater than or equal to $100 \mathrm{mg} / \mathrm{L}$ may induce differential organ development. In post-hatch growth, the replacement 
of the standard level of $\mathrm{ZnO}$ (55 mg/kg) with 100\% NanoZnO in the diet increased the chickens' BW, but to the same level as in the group without $\mathrm{ZnO}$ supplementation. Furthermore, NanoZnO did not reduce the content of $\mathrm{Zn}$ in faeces, which was only significantly lower in the group without $\mathrm{ZnO}$ supplementation in comparison with other groups. The results indicate that the replacement of $\mathrm{ZnO}$ with NanoZnO has no negative effects on chicken growth.

\section{Acknowledgements} Poland.

This work was supported by grant 267659 'Gutfeed' from the National Centre for Research and Development,

\section{Authors' Contributions}

ES conceived the study and helped draft the manuscript. MŁ carried out chicken experiments and drafted the manuscript. A $Ł$ conducted statistical analyses and edited the draft version of the manuscript. AC participated in the statistical analyses and prepared the final manuscript. NHC participated in the evaluation of data and manuscript preparation. JN participated in the design and coordination of experiments. AM participated in chicken experiments and data collection. MS and MW carried out embryo experiments and participated in the evaluation of data. MZ performed and evaluated blood analyses and participated in embryo experiments..

\section{Conflict of Interest Declaration}

No potential conflicts of interest were reported by the authors.

\section{References}

Ahmadi, F., Ebrahimnezhad, Y., Sis, N.M. \& Ghalehkandi J.G., 2013. The effects of zinc oxide nanoparticles on performance, digestive organs and serum lipid concentration in broiler chickens during starter period. Int. J. Biosci. 3(7), 23-29.

Ali, S., Masood, S., Zaneb, H., Faseeth-ur-Rehman, H., Masood, S., Khan, M., Tahir, S.K. \& Rehman, H., 2017. Supplementation of zinc oxide nanoparticles has beneficial effects on intestinal morphology in broiler chicken. Pak. Vet. J. 37(3), 335-339.

Anjum, N.A., Rodrigo, M.A.M., Moulik, A., Heger, Z., Kopel, P., Zítka, O., Adam, V., Lukatkin, A.S., Duarte, A.C., Pereira, E. \& Kizek, R., 2016. Transport phenomena of nanoparticles in plants and animals/humans. Enviro. Res. 151, 233-243.

Asheer, M.N.A., 2017. Effect of dietary nano zinc oxide supplementation on performance of broilers. MVSc thesis, Maharashtra Animal and Fishery Sciences University, Nagpur, India.

Badawi, M., Ali, M. \& Behairy, A., 2017. Effects of zinc sources supplementation on performance of broiler chickens. J. Am. Sci. 13(7), 35-43.

Bami, M.K., Afsharmanesh, M., Salarmoini, M. \& Tavakoli, H., 2018. Effect of zinc oxide nanoparticles and Bacillus coagulans as probiotic on growth, histomorphology of intestine, and immune parameters in broiler chickens. Comp. Clin. Path. 27, 399-406.

Chattopadhyay, K., Mondal, M.K. \& Roy, B., 2006. Comparative efficacy of DL-methionine and herbal methionine on performance of broiler chicken. Int. J. Poult. Sci. 5(11), 1034-1039.

Fathi, M., 2016. Effects of zinc oxide nanoparticles supplementation on mortality due to ascites and performance growth in broiler chickens. Iran J. Appl. Anim. Sc. 6(2), 389-394.

Gopi, M., Pearlin, B., Kumar, R.D., Shanmathy, M. \& Prabakar, G., 2017. Role of nanoparticles in animal and poultry nutrition: Modes of action and applications in formulating feed additives and food processing. Int. J. Pharm. 13(7), 724-731.

Hassan, A.M., 2018. Effect of in ovo injection with nano-selenium or nano-zinc on post-hatch growth performance and physiological traits of broiler chicks. Int. J. Env. Agr. Biotech. 3(2), 350-357.

Josuha, P.P., Valli, C. \& Balakrishnan, V., 2016. Effect of in ovo supplementation of nano forms of zinc, copper, and selenium on post-hatch performance of broiler chicken. Vet. World 9(3), 287-294.

Khah. M.M., Ahmadi, F. \& Amanlou, H., 2015. Influence of dietary different levels of zinc oxide nano particles on the yield and quality carcass of broiler chickens during starter stage. Indian J. Anim. Sci. 85(3), 287-290.

Korhonen, A., Hemminki, K. \& Vainio, H., 1982. Application of the chicken embryo in testing for embryotoxicity. Scand. J. Work, Environ. Health 8, 63-69.

Lina, T., Jianyang, J., Fenghua, Z., Huiying, R. \& Wenli, L., 2009. Effects of nano-zinc oxide on the performance and dressing performance of broiler. Chinese Agr. Sci. Bull. 02. Category Index: S831

Lucht, H.L., Casey, N.H. \& Sawosz, E., 2018. Survival and development of embryos of Gallus gallus domesticus treated with inorganic bromide. S. Afr. J. Anim. Sci. 48(3), 583-589.

Mishra, A., Swain, R.K., Mishra, S.K., Panda, N. \& Sethy, K., 2014. Growth performance and serum biochemical parameters as affected by nano zinc supplementation in layer chicks. Indian J. Anim. Nutr. 31, 384-388.

Mohammadi, V., Ghazanfari, S., Mohammadi-Sangcheshmeh, A. \& Nazaran, M.H., 2015. Comparative effects of zincnano complexes, zinc-sulphate and zinc-methionine on performance in broiler chickens. Br. Poult. Sci. 56(4), 486493.

Mroczek-Sosnowska, N., Łukasiewicz, M., Adamek, D., Kamaszewski, M., Niemiec, J., Wnuk-Gnich, A., Scott A., Chwalibog A. \& Sawosz, E., 2017. Effect of copper nanoparticles administered in ovo on the activity of proliferating cells and on the resistance of femoral bones in broiler chickens. Arch. Anim. Nutr. 71(4), 327-332. 
Mroczek-Sosnowska, N., Łukasiewicz, M., Wnuk, A., Sawosz, E., Niemiec, J., Skot, A., Jaworski, S. \& Chwalibog, A., 2015a. In ovo administration of copper nanoparticles and copper sulfate positively influences chicken performance: Effect of Cu on chicken performance. J. Sci. Food. Agri. 96, 3058-3062.

Mroczek-Sosnowska, N., Sawosz, E., Vadalasetty, K.P., Łukasiewicz, M., Niemiec, J., Wierzbicki, M., Kutwin, M., Jaworski, S. \& Chwalibog, A., 2015b. Nanoparticles of copper stimulate angiogenesis at systemic and molecular level. Int. J. Mol. Sci. 16, 4838-4849.

NRC (National Research Council), 1994. Nutrient Requirements of Poultry. 9th revised edition. National Academic Press. Washington, DC, USA.

Pineda, L., Chwalibog, A., Sawosz, E., Lauridsen, C., Engberg, R., Elnif, J., Hotowy, A., Sawosz, F., Gao, Y., Ali, A. \&

Moghadam, H.S., 2012. Effect of silver nanoparticles on growth performance, metabolism and microbial profile of broiler chickens. Arch. Anim. Nutr. 66, 416-429.

Pineda, L., Sawosz, E., Vadalasetty, K.P. \& Chwalibog, A., 2013. Effect of copper nanoparticles on metabolic rate and development of chicken embryos. Anim. Feed. Sci. Tech. 186, 125-129.

Sahoo, A., Swain, R.K., Mishra, S.K., Behura, N.C., Beura, S.S., Sahoo, C., Das, A., Mishra, A., \& Jena, B., 2016. Growth feed conversion efficiency, and carcass characteristics of broiler chicks fed on inorganic, organic and nano zinc supplemented diets. Anim. Sci. Rep. 10(1), 10-18.

Sahoo, A., Swain, R.K. \& Mishra, S.K., 2014. Effect of inorganic and nano zinc supplemented diets on bioavailability and immunity status of broilers. Int. J. Adv. Res. 2(11), 828-837.

Sawosz, E., Jaworski, S., Kutwin, M., Hotowy, A., Wierzbicki, M., Grodzik, M., Kurantowicz, N., Strojny, B., Lipińska, L., \& Chwalibog, A., 2014. Toxicity of prestine graphene in experiments in a chicken embryo model. Int. Jnl. Nanomed. 9, 3913-3922.

Sawosz, E., Łukasiewicz, M., Łozicki, A., Sosnowska, M., Jaworski, S., Niemiec, J., Scott, A., Jankowski, J., Józefiak, D. \& Chwalibog, A., 2018. Effect of copper nanoparticles on the mineral content of tissues and droppings, and growth of chickens. Arch. Anim. Nutr. DOI: 10.1080/1745039X.2018.1505146

Scott, A., Vadalasetty, K.P., Chwalibog, A. \& Sawosz, E., 2018. Copper nanoparticles as an alternative feed additive in poultry: A review. Nanotechnol Rev. 7(1), 69-93.

Scott, A., Vadalasetty, K.P., Łukasiewicz, M., Jaworski, S., Wierzbicki, M., Chwalibog, A. \& Sawosz, E., 2017. Effect of different levels of copper nanoparticles and copper sulphate on performance, metabolism and blood biochemical profiles in broiler chicken. J Anim Physiol Anim Nutr DOI: 10.1111/jpn.12754.

Scott, A., Vadalasetty, K.P., Sawosz, E., Łukasiewicz, M., Vadalasetty, R.K.P., Jaworski, S. \& Chwalibog, A., 2016. Effect of copper nanoparticles and copper sulphate on metabolic rate and development of broiler embryos. Anim. Feed Sci. Tech. 220, 151-158.

Swain, P., Rao, S.B.N., Rajendarm, D., Dominic, G. \& Selvaraju, S., 2016. Nano zinc, as alternative to conventional zinc as animal feed supplement: A review. Anim. Nutr. 2:134-141.

Zhao, C-Y., Tan, S-X., Xiao, X-Y., Qiu, X-S., Pan, J-Q. \& Tang, Z-X., 2014. Effects of dietary zinc oxide nanoparticles on growth performance and antioxidative status in broilers. Biol. Trace Elem. Res. 160, 361-367. 